\title{
Testing safety of genetically modified products of rice: Case study on Sprague Dawley rats
}

\author{
Mehrnoush S. ${ }^{1}$, Orlov Y.L. ${ }^{2}$, Eslami G. ${ }^{1 *}$, Hajimohammadi B. ${ }^{1}$, Ehrampoush M.H. ${ }^{1}$, \\ Rezvani M.E. ${ }^{1}$, Fallahzadeh H. ${ }^{1}$, Zandi H. ${ }^{1}$, Hosseini S.S. ${ }^{1}$, Ahmadian S. ${ }^{1}$, \\ Mortazavi S. ${ }^{1}$, Fallahi R. ${ }^{3}$, Asadi-Yousefabad S.-L. ${ }^{1}$ \\ ${ }^{1}$ Shahid Sadoughi University of Medical Sciences, Yazd, Iran \\ ${ }^{2}$ Institute of Cytology and Genetics, SB RAS, Novosibirsk, Russia \\ ${ }^{3}$ Razi Vaccine and Serum Research Institute, Karaj, Iran \\ *e-mail:eslami_g2000@yahoo.com
}

Rice is the staple food of more than half the world's population. However, rice is one of the products that are severely damaged by pests. In order to stand against this damaged, genetic engineering is considered as one of the best ways by adding new genes inside the grain named genetically modified (GM) foods. It is important to find any additional genes in tissues after consumption of GM foods. Therefore, in this study, the remaining of cryIA $(b)$ gene and P35 were assessed in the liver of Sprague Dawley rats fed with GM rice. Overall, 20 male and 20 female SD rats were fed by pellets made by GM rice in $50 \%$ of needed carbohydrate for 90 days. Then, sampling was done from liver. DNA extraction was done based on the protocol. The quality and quantity of the extracted DNA was done by agarose gel electrophoresis and spectrophotometery, respectively. Detection of GM genes residues, including $\operatorname{CryIA(b)}$, P35, and T35 was done by Polymerase Chain Reaction using specific primer pairs. The results were analyzed by agarose gel electrophoresis alongside with $50 \mathrm{bp}$ DNA ladder. The results were compared with the ones in control groups with feeding by standard pellet. All tests were done in triplicates. Analysis of the amplification of P35, CryIA(b) and T35 showed no residues inside the liver tissue. The results showed no significant difference in the presence of transgenic gene in the liver tissue between the control and experiment groups. Therefore, this study rejects the possibility of gene settle of GM rice gene residues in liver tissue. Acknowledgements: The authors are grateful from Research Center for Food Hygiene and Safety. 